\title{
Pharmacological Modulation of Long Cardiac QT Interval in Ex Vivo and in Vitro Experimental Models
}

\author{
Maria Consiglia Trotta*, Rosa Maisto, Nicola Perrotta, Michele D’Amico and Clara Di Filippo \\ Department of Experimental Medicine, University of the Studies of Campania "Luigi Vanvitelli", Italy
}

Submission: April 16, 2018; Published: May 01, 2018

"Corresponding author:Maria Consiglia Trotta, Department of Experimental Medicine, University of the Studies of Campania "LuigiVanvitelli", Naples, Italy, Tel: +390815667530; Email: mariaconsiglia.trotta2@unicampania.it

\begin{abstract}
Prolongation of cardiac QT interval is one of the most dangerous consequences of hyperglycemia, acting on accumulation of reactive oxygen species and impairment of ionic pumps. Previous studies showed that the selective inhibition of the endogenous aldose reductase 2 (ALR2) activities, responsible of the oxidative heart damage following diabetes, could be a therapeutic treatment for the high glucose-related cardiac alterations. Indeed, the newly synthetized ALR2 inhibitor, the benzofuroxane derivative 5(6)-(benzo[d]thiazol-2-ylmethoxy)benzofuroxane (BF-5m), dose-dependently reduced the long cardiac QT interval in isolated rat hearts perfused with high glucose, by increasing in parallel the expression and activity of endogenous antioxidant pathways and free radical scavengers such as SIRT1 and its targets MnSOD and FOXO-1. The reduction of the oxidative stress induced by BF-5m lead also modifications of the expression of KCNQ1/KCNE1 potassium channels subunits in H9c2 cardiomyocytes exposed to high glucose, modifying the expression levels of miR-1, involved in KCNQ1 and KCNE1 expression.
\end{abstract}

Keywords: Long QT interval; Potassium ion channels; Hyperglycemia; ALR2 inhibition

Abbreviations: LQTS: Long QT Syndrome; CPCs: Cardiac Progenitor Cells; ALR2- Aldose Reductase 2; ROS- Reactive Oxygen Species; SDHSorbitol Dehydrogenase; SIRT1- Sirtuin1; TNF- $\alpha$ - Tumor Necrosis Factor Alfa; MnSOD- Manganese Superoxide-Dismutase; FOXO 1- Forkhead Transcription Factor 1; PKC- Protein Kinase C

\section{Long QT Interval}

Prolongation of cardiac QT interval, characterized by abnormal QT duration on the surface ECG (higher than $450 \mathrm{msec}$ in male and $470 \mathrm{msec}$ in female adults), is an inherited cardiac pathology caused by disorders of the expression and functionality of cardiac ion channels [1-3]. About the $90 \%$ of Long QT Syndrome (LQTS) cases are related to alterations of the 3 main genes codifying cardiac sodium and potassium channels: KCNQ1, KCNH2 and SCN5A genes [4,5]. Mutations in KCNQ1, encoding the $\alpha$-subunit of the K+ channel Kv7.1, affect the slow delayed rectifier potassium (IKs) current, creating a highly arrhythmogenic condition characteristic of the Long QT Syndrome type 1 (LQTS1), frequently triggered by stress and physical exercise (above all swimming) [6-8]. Conversely, mutations in $\mathrm{KCNH} 2$, encoding the $\alpha$-subunit of the $\mathrm{K}+$ channel conducting the IK rectifier ( $\mathrm{IKr}$ ) current, lead to a reduction in IKr current and are associated to Long QT Syndrome type 2 (LQTS2) events, occurring during arousal, especially from auditory stimuli at rest, such as sudden noises and telephone ringing $[8,9]$. KCNQ1 and $K C N H 2$ function can be altered also by mutations occurring in genes codifying their main ancillary single-transmembrane $\beta$-subunits, KCNE1 and KCNE2, encoding the minimal $\mathrm{K}+$ ion channel and the minimal $\mathrm{K}+$ ion channelrelated peptide 1 [9]. Finally, mutations in SCN5A increase the delayed $\mathrm{Na}+$ inward current, prolonging the action potential duration and are related to Long QT Syndrome type 3 (LQTS3), occurring in patients asleep or at rest $[9,10]$.

\section{Hyperglycemia Contribution to QT Interval Prolongation}

One of the most important risk factor influencing Long QT prolongation is hyperglycemia: high glucose levels leads to ventricular instability both in healthy and non diabetic patients and to significant haemodynamic and electric perturbations in streptozotocin-diabetic rats, interestingly reversed by the freeradicals scavenger glutathione [11-14]. Particularly, alterations of IKs current, leading to LQTS1, the most frequent type of Long QT Syndrome, are strictly related to hyperglycemic conditions: hyperglycemia, by elevating miR-1/133 expression in cardiac progenitor cells (CPCs), reduces KCNQ1 and KCNE1 levels, consequently impairing IKs [15]. Moreover, at level of coronary artery, hyperglycemia down-regulates KV7 potassium channels, influencing their reactivity $[16,17]$. These studies paved the way to a direct and key role of elevated free radical production induced by hyperglycemia in potassium channels-linked QT interval prolongation.

\section{Activation of Aldose Reductase 2 by Hyperglycemia}

One of the most important mechanisms through which hyperglycemia contributes to free radicals induction is the activation of aldose reductase 2 (ALR2), the first enzyme of the 
polyol pathway [18]. While under normoglycemic conditions (3.8-6.1 mmol/L) only about $3 \%$ of cellular glucose is converted to $\mathrm{s}$ orbital by ALR2, when hyperglycemic conditions occur ( $>7$ $\mathrm{mmol} / \mathrm{L}$ ) more than $30 \%$ of glucose is shunted to the polyol pathway. This conversion generates reactive oxygen species (ROS) because ALR2 reduces glucose into $s$ orbital at the expense of NADPH, essential for generation of the intracellular antioxidant gluthatione (GSH) [19-21]. Moreover, in the consequent reactions, the conversion of sorbitol to fructose by sorbitol dehydrogenase (SDH) depletes the amount of NAD+, an important co-factor of Sirtuin1 (SIRT1). This deacetylase shows anti-oxidant effects and is also involved in the regulation of glucose consumption by regulating insulin expression $[22,23]$.

\section{Aldose Reductase 2 in Diabetes Cardiovascular Diseases}

ALR2 plays a critical role in diabetes cardiovascular complications, as suggested by a number of evidences. ALR2 activation leads to hyper aggregation of diabetic platelets [18] and potentially mediates diabetes-induced acceleration of atherogenesis and endothelial dysfunction in humans, by increasing intracellular oxidative stress, translocation and phosphorylation of signaling targets, release of Tumor necrosis factor alfa (TNF- $\alpha$ ) and related cytokines [2426]. Moreover, hyperglycemia-increased ALR2 activity may exacerbate myocardial dysfunction, inducing cardiac myocyte apoptosis through hyper osmotic stress and leading to diabetic cardiomyopathy [27]. Hence, the inhibition of ALR2 can prevent or delay the progression of hyperglycemia-induced cardiovascular diseases. In particular, evidences have shown that the inhibition of ALR2 reduces the detrimental effects of high glucose levels on the expression of cardiac ion channels KCNQ1/ KCNE1, conducting IKs current and responsible of QT duration.

\section{Aldose Reductase 2 Selective Inhibitors}

Since the discovery of ALR2, a huge amount of experimental data clearly proved the effectiveness of ALR2 inhibitors (ARIs) in treating hyperglycemia-induced pathologies like neuropathy, nephropathy, retinopathy, and cataract. To date, the main examples of active compounds undergone clinical trials are spiroderivatives, like fidarestat and ranirestat; while epalrestat, an acid acetic compound, is currently marketed for the treatment of diabetic neuropathy, retinopathy and nephropathy [28-31]. Nonetheless, the development of a number of compounds has been hampered by low in vivo efficacy and side effects, such as skin reactions or liver toxicity, some of these were withdrawn from clinical trials; as example, sorbinil, imirestat and tolrestat were introduced on the market and then withdrawn [32,33]. Among the chemical entities tested as potential ALR2 inhibitors by Cosconati et al. [34] with few or no side effects, the benzo[c] $[1,2,5]$ oxadiazole derivative KM07100 emerged as the most intriguing candidate [34]. This compound is characterized by a core never exploited before and unpredicted to pose the risk of failure shown by most ARIs, because of either pharmacokinetic restrictions or unwanted side effects. Starting from the benzo[c] $[1,2,5]$ oxadiazole synthetic precursor, the benzofuroxane, characterized by nitric oxide (NO) donor, vasorelaxant, and platelet anti-aggregating activities [35], a series of novel benzofuroxane derivatives were synthesized fusing the benzofuroxane ring with aromatic and lipophilic groups [33]. All the synthesized compounds were extensively evaluated by Sartini et al. [33] for ALR2 inhibitory activity and selectivity, as well as for their ability to generate NO and efficacy in ROS scavenging. The derivative 5(6)-(benzo[d]thiazol-2-ylmethoxy) benzofuroxane, or from now called BF-5m, emerged for the excellent correlation between its high ALR2 inhibitory activity and significant NO donor and ROS scavenger, possibly being a multieffective agent for the treatment of hyperglycemia-induced QT interval prolongation [33].

BF-5m reduces QT Interval Prolongation by Modifying Cardiac Plasma Membrane KCNQ1 and KCNE1 Levels

Ex vivo and in vitro experimental settings studied the effects of BF-5m in hyperglycemia-induced QT interval prolongation. Di Filippo et al. [36] showed that in Langendorff's isolated rat hearts, perfused with high glucose concentration ( $33 \mathrm{mM}), \mathrm{BF}-5 \mathrm{~m}$ administration was able to reduce the prolongation of cardiac QT interval and CPP values induced by hyperglycemia. Moreover, BF$5 \mathrm{~m}$ reduced the structural and functional cardiac derangement caused by high glucose, by increasing the expression and activity of the endogenous antioxidant and free radical scavenger SIRT1. This evidence also confirmed by the increase in the SIRT1 targets Manganese Superoxide-Dismutase (MnSOD) and in Forkhead transcription factor 1 (FOXO-1), a transcription factor regulated by SIRT1 and involved in the modulation of gluconeogenesis, glycogenolysis, and adipogenesis [37]. These observations were then translated on cultured embryonic rat heart ventricle $\mathrm{H} 9 \mathrm{c} 2$ cells exposed high glucose stimulus, exploring a possible effect of the decreased ROS levels on Iks current conduction, responsible of QT interval duration. Trotta et al. [38] showed for the first time that the blockade of the ALR2 with BF-5m leads to changes in KCNQ1/KCNE1 potassium channel subunits expression, during the exposure of $\mathrm{H} 9 \mathrm{c} 2$ cells to high glucose. Indeed, BF$5 \mathrm{~m}$ dose-dependently increased plasmatic KCNE1 and KCNQ1 levels and this was paralleled by a significant down-regulation of miR-1 levels. This miRNA, showing a higher expression after hyperglycemia stimulation, has been found to provoke cardiac arrhythmias by altering potassium current in mature myocytes, reducing he expression of its targets KCNQ1 and KCNE1 [39]. The ability shown by BF-5m to restore plasmatic KCNE1 and KCNQ1 levels by up-regulating miR-1 expression is novel evidence, since there was no correlation linking ALR2 to miR-1 or KCNpotassium channels. Interestingly, this occurring on the plasma membrane but not on mitochondrial membrane. This was quite surprising, considering that both prolongation of cardiac QT interval and hyperglycemia have been associated to alterations of mitochondrial respiratory chain complex $[40,41]$. Indeed, under high glucose stimulus, the activation of protein kinase C (PKC) isoforms induces ALR2 phosphorylation and translocation to the 
mitochondria membrane [42,43], whereALR2 contributes to high glucose-mediated mitochondrial dysfunction. Moreover, new evidences suggest that after the translocation on mitochondrial membrane, ALR2 could lead to alterations of ion channels expression through the phosphorylation and activation of p53 [44]. This was recently confirmed by Testai et al. [45] proving that, in line with our evidences, KCNQ4 (or Kv7.4) channels are the only potassium channels exerting a significant cardioprotective role in rat cardiac mitochondria against ischemia/ reperfusion. Finally, the putative preservation of the myocyte normal electrical activity induced by BF-5m in the in vitro $\mathrm{H} 9 \mathrm{c} 2$ setting was also supported by the improvement of the sharply demarcated and stretched elongated morphology, characteristic of cardiomyocytes grown in hyperglycemic conditions and the preservation of the cell biology after BF-5m exposure.

\section{Conclusion}

In conclusion, data from both ex vivo and in vivo settings suggest that the new aldose ALR2 inhibitor benzofuroxane derivative BF-5m may supply cardioprotection from high glucose-induced cardiac QT interval prolongation by reducing the detrimental effects caused by the oxidative stress on cardiac tissue. Consequently, by down-regulating miR-1, BF-5m restores plasma membrane KCNE1 and KCNQ1 levels, conducting Iks current, responsible of QT interval duration (Figure 1).

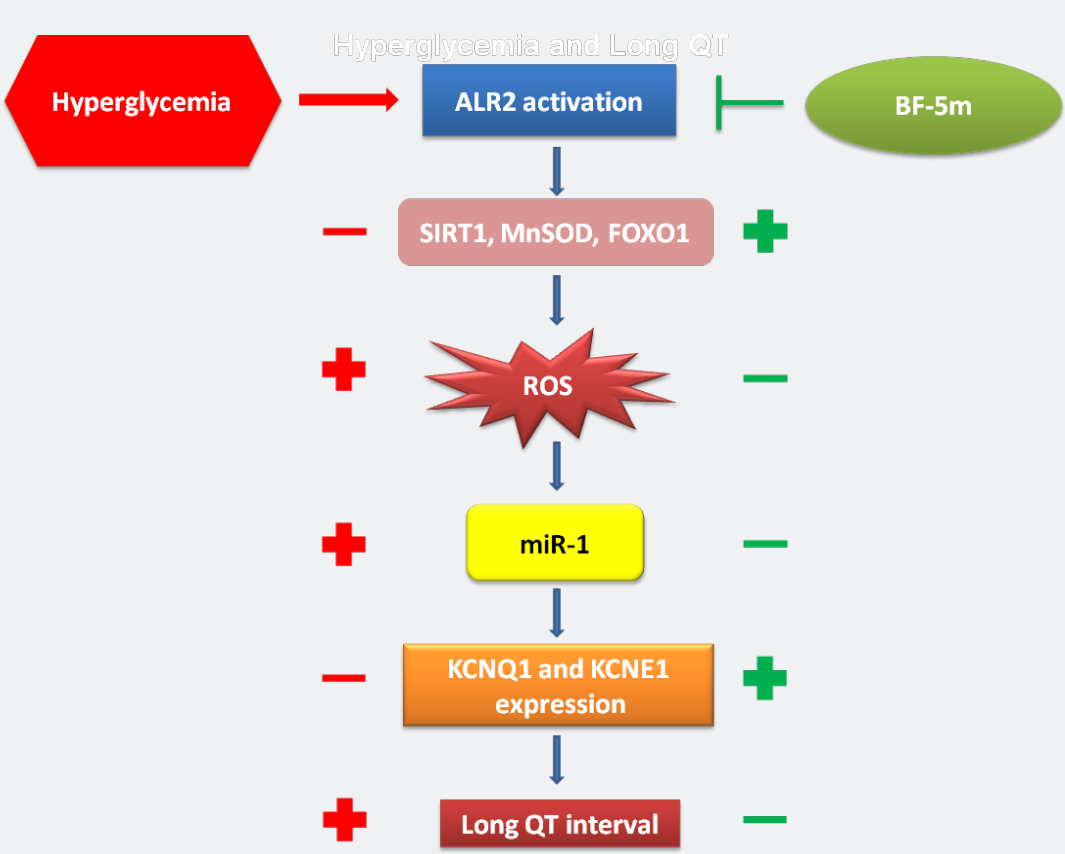

Figure 1: By activating ALR2, hyperglycemia depletes cellular antioxidant defenses, favoring ROS accumulation and increasing miR-1 levels. This leads to a reduction of KCNQ1/KCNE1 plasma membrane expression, prolonging QT interval (in red at left). By selectively inhibiting ALR2 activity, BF-5m restores the antioxidant enzymes, lowering ROS levels and resulting in decreased miR-1 levels. The consequent higher cardiac KCNQ1/KCNE1 plasma membrane expression reduces IKs current alterations and favors a normal QT interval duration (in green at right).

\section{References}

1. Johnson JN, Ackerman MJ (2009) QTc: how long is too long? Br J Sports Med 43(9): 657-662.

2. Schwartz PJ, Stramba Badiale M, Crotti L, Pedrazzini M, Besana A, et al. (2009) Prevalence of the congenital long-QT syndrome. Circulation 120:1761-1767.

3. Abrams DJ, MacRae CA (2014) Long QT Syndrome. Circulation 129:1524-1529.

4. Tester DJ, Will ML, Haglund CM, Ackerman MJ (2005) Compendium of cardiac channel mutations in 541 consecutive unrelated patients referred for long QT syndrome genetic testing. Heart Rhythm 2(5): 507-517.

5. Kapplinger JD, Tester DJ, Salisbury BA, Carr JL, Harris Kerr C, et al. (2009) Spectrum and prevalence of mutations from the first 2,500 consecutive unrelated patients referred for the FAMILION long QT syndrome genetic test. Heart Rhythm 6(9): 1297-1303.
6. Jervell A, Lange Nielsen F (1957) Congenital deaf-mutism, functional heart disease with prolongation of the Q-T interval and sudden death. Am Heart J 54(1): 59-68.

7. Schwartz PJ, Spazzolini C, Crotti L, Bathen J, Amlie JP, et al. (2006) The Jervell and Lange-Nielsen syndrome: natural history, molecular basis, and clinical outcome. Circulation 113: 783-790.

8. Schwartz PJ, Priori SG, Spazzolini C (2001) Genotype-phenotype correlation in the long-QT syndrome: gene-specific triggers for lifethreatening arrhythmias. Circulation 103: 89-95.

9. Schwartz PJ, Crotti L, Insolia R (2012) Long QT Syndrome from genetics to management. Circ Arrhythm Electrophysiol 5(4): 868-877.

10. Bennett PB, Yazawa K, Makita N, George AL (1995) Molecular mechanism for an inherited cardiac arrhythmia. Nature 376(6542): 683-685.

11. Gordin D, Forsblom C, Rönnback M, Groop PH (2008) Acute hyperglycaemia disturbs cardiac repolarization in Type 1 diabetes. Diabet Med 25(1): 101-105. 
12. Marfella R, Nappo F, De Angelis L, Siniscalchi M, Rossi F, et al. (2000) The effect of acute hyperglycemia on QTc duration in healthy man. Diabetologia 43(5): 571-575.

13. Dekker JM, Feskens EJM, Schouten EG, Klootwijk P, Pool J, et al. (1996) The Zutphen Elderly Study: QTc duration is associated with levels of insulin and glucose tolerance. Diabetes 45(3): 376-380.

14. D Amico M, Marfella R, Nappo F, Di Filippo C, De Angelis L, et al. (2001) High glucose induces ventricular instability and increases vasomotor tone in rats. Diabetologia 44(4): 464-470.

15. Li Y, Yang CM, Xi Y, Wu G, Shelat H, et al. (2013) MicroRNA-1/133 targeted dysfunction of potassium channels KCNE1 and KCNQ1 in human cardiac progenitor cells with simulated hyperglycemia. Int J Cardiol 167(3): 1076-1008.

16. Morales Cano D, Moreno L, Barreira B , Pandolfi R , Chamorro V, et al (2015) Kv7 channels critically determine coronary artery reactivity: left-right differences and down-regulation by hyperglycaemia. Cardiovasc Res 106(1): 98-108.

17. Morales Cano D, Moreno L, Barreira B, Briones AM, Pandolfi R, et al. (2016) Activation of PPAR $\beta / \delta$ prevents hyperglycaemia-induced impairment of Kv7 channels and cAMP-mediated relaxation in rat coronary arteries. Clin Sci Lond 130(20): 1823-1836.

18. El-Kabbani O, Ruiz F, Darmanin C, Chung RP (2004) Aldose reductase structures: implications for mechanism and inhibition. Cell Mol Life Sci 61: 750-762.

19. Tang WH, Martin KA, Hwa J (2012) Aldose Reductase, Oxidative Stress, and Diabetic Mellitus. Front Pharmacol 3: 87.

20. Yabe Nishimura C (1998) Aldose reductase in glucose toxicity: a potential target for the prevention of diabetic complications. Pharmacol Rev 50(1): 21-33.

21. Veeresham C, Rama Rao A, Asres K (2014) Aldose reductase inhibitors of plant origin. Phytotherapy Research 28(3): 317-333.

22. Guarente L, Franklin H (2011) Epstein Lecture: Sirtuins, aging, and medicine. N Engl J Med 364(23): 2235-2244.

23. Chakrabarti SK, Francis J, Ziesmann SM, Ziesmann SM, Garmey JC, Mirmira RG, et al. (2003) Covalent histone modifications underlie the developmental regulation of insulin gene transcription in pancreatic beta cells. J Biol Chemistry 278(26): 23617-23623.

24. Ramana KV, Friedrich B, Tammali R, West MB, Bhatnagar A, et al. (2005) Requirement of aldose reductase for the hyperglycemic activation of protein kinase $\mathrm{C}$ and formation of diacylglycerol in vascular smooth muscle cells. Diabetes 54(3): 818-829.

25. Srivastava S, Ramana KV, Tammali R, Srivastava SK, Bhatnagar A, et al. (2006) Contribution of aldose reductase to diabetic hyperproliferation of vascular smooth muscle cells. Diabetes 55(4): 901-910.

26. Reddy AB, Ramana KV, Srivastava S, Bhatnagar A, Srivastava SK (2009) Aldose reductase regulates high glucose-induced ectodomain shedding of tumor necrosis factor (TNF)-alpha via protein kinase $\mathrm{C}$-delta and TNF-alpha converting enzyme in vascular smooth muscle cells. Endocrinology 150(1): 63-74.

27. Galvez AS, Ulloa JA, Chiong M, Criollo A, Eisner V, et al. (2003) Aldose reductase induced by hyperosmotic stress mediates cardiomyocyte apoptosis: differential effects of sorbitol and mannitol. J Biol Chem 278(40): 38484-38494

28. Asano T, Saito Y, Kawakami M , Yamada N ,et al. (2002) Fidarestat (SNK-860), a potent aldose reductase inhibitor, normalizes the elevated sorbitol accumulation in erythrocytes of diabetic patients. J Diabetes Complications 16(2): 133-138.

29. Bril V, Hirose T,Tomioka S , Buchanan R, et al. (2009) The Ranirestat Study Group. Ranirestat for the management of diabetic sensorimotor polyneuropathy. Diabetes Care 32(7): 1256-1260.
30. Ramirez MA, Borja NL (2008) Epalrestat: An aldose reductase inhibitor for the treatment of diabetic neuropathy. Pharmacotherapy 28(5): 646-655.

31. Hotta N, Kawamori R, Fukuda M, Shigeta Y, et al. (2012) longterm clinical effects of epalrestat, an aldose reductase inhibitor, on progression of diabetic neuropathy and other microvascular complications: Multivariate epidemiological analysis based on patient background factors and severity of diabetic neuropathy. Diabet Med 29(12):1529-33.

32. Sun W, Oates PJ, Coutcher JB, C Gerhardinger, M Lorenzi, et al(2006) A selective aldose reductase inhibitor of a new structural class prevents or reverses early retinal abnormalities in experimental diabetic retinopathy. Diabetes 55(10): 2757-2762.

33. Sartini S, Cosconati S, Marinelli L, Barresi E, Di Maro S, et al. (2012) Benzofuroxane derivatives as multi-effective agents for the treatment of cardiovascular diabetic complications. Synthesis, functional evaluation, and molecular modeling studies. J Med Chem 55(23): 10523-10531.

34. Cosconati S, Marinelli L, La Motta C, Stefania S, Federico D S ,et al. (2009) Pursuing aldose reductase inhibitors through in situ crossdocking and similarity-based virtual screening. J Med Chem 52(18): 5578-5581.

35. Gosh P, Ternai B, Whitehouse M (1981) Benzofurazans and benzofuroxans: Biochemical and pharmacological properties. Med Res Rev 1(2): 159-187.

36. Di Filippo C, Ferraro B, Maisto R (2016) Effects of the New Aldose Reductase Inhibitor Benzofuroxane Derivative BF-5m on High Glucose Induced Prolongation of Cardiac QT Interval and Increase of Coronary Perfusion Pressure. J Diabetes Res 2016:5281267.

37. Nakae J, Kitamura T, Kitamura Y, Biggs WH, Arden KC, et al. (2003) The forkhead transcription factor Foxo1 regulates adipocyte differentiation. Developmental Cell 4(1): 119-129.

38. Trotta MC, Salerno M, Brigida AL, Monda V, Messina A, et al. (2018) Inhibition of aldose-reductase- 2 by a benzofuroxane derivative bf- $5 \mathrm{~m}$ increases the expression of kcne1, kcnq1 in high glucose cultured H9c2 cardiac cells and sudden cardiac death. Oncotarget 9:1725717269.

39. Yang B, Lin H, Xiao J, Lu Y, Luo X, et al (2007) The muscle-specific micro RNA miR-1 regulates cardiac arrhythmogenic potential by targeting GJA1 and KCNJ2. Nat Med 13(4): 486-491.

40. Baik R, Chae JH, Lee YM, Kang HC, Lee JS, et al. (2010) Electrocardiography as an early cardiac screening test in children with mitochondrial disease. Korean J Pediatr 53(5): 644-647.

41. Ninkovic VM, Ninkovic SM, Miloradovic V, D Stanojevic, Marijana B, et al. (2016) Prevalence and risk factors for prolonged QT interval and QT dispersion in patients with type 2 diabetes. Acta Diabetol 53(5): 737-744.

42. Varma T, Liu SQ, West M, Thongboonkerd V, Ruvolo PP, et al (2003) Protein kinase C-dependent phosphorylation and mitochondrial translocation of aldose reductase. FEBS Lett 534(1-3): 175-179.

43. Rolo AP, Palmeira CM (2006) Diabetes and mitochondrial function: role of hyperglycemia and oxidative stress. Toxicol Appl Pharmacol 212(2): 167-178.

44. Tang WH, Stitham J, Jin Y, Liu R, Lee SH, et al. (2014) Aldose reductasemediated phosphorylation of p53 leads to mitochondrial dysfunction and damage in diabetic platelets. Circulation 129(15):1598-1609.

45. Testai L, Barrese V, Soldovieri MV, Ambrosino P, Martelli A, et al. (2016) Expression and function of Kv7.4 channels in rat cardiac mitochondria: possible targets for cardioprotection. Cardiovasc Res 110 (1): 40-50. 
This work is licensed under Creative Commons Attribution 4.0 License
Your next submission with Juniper Publishers will reach you the below assets

- Quality Editorial service

- Swift Peer Review

- Reprints availability

- E-prints Service

- Manuscript Podcast for convenient understanding

- Global attainment for your research

- Manuscript accessibility in different formats

( Pdf, E-pub, Full Text, Audio)

- Unceasing customer service

Track the below URL for one-step submission https://juniperpublishers.com/online-submission.php 